\title{
Patrones de escurrimiento en la Cuenca Lechuguilla- Ohuira-Navachiste, Sinaloa, asociados a cambios de uso del suelo: Una aproximación con el modelo del número de curva
}

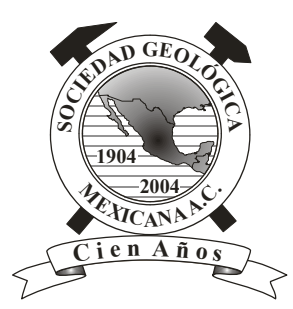

\author{
César A. Berlanga-Robles ${ }^{1, *}$, Arturo Ruiz-Luna ${ }^{1}$, Hugo Orlando Covarrubias- \\ Legaspi ${ }^{2}$, Rafael Hernández-Guzmán ${ }^{3}$
}

\author{
${ }^{1}$ Centro de Investigación en Alimentación y Desarrollo A.C., Unidad Mazatlán en Acuicultura y Manejo \\ Ambiental, Av. Sábalo Cerritos s/n, Mazatlán, 82010, Sin., México \\ ${ }^{2}$ Universidad de Guadalajara, Centro Universitario de Ciencias Biológicas y Agropecuarias, Las Agujas, Zapopan, \\ 45110, Jal., México \\ ${ }^{3}$ Posgrado en Ciencias del Mar y Limnología, UNAM, Unidad Académica Mazatlán, Av. Joel Montes Camarena \\ s/n., Mazatlán, 82040, Sin., México \\ * cesar@ciad.mx
}

\section{Resumen}

Se integró un sistema de información geográfica (SIG) con mapas temáticos de cobertura y usos del suelo, cartas edafológicas y registros históricos de precipitación, para analizar las tendencias de cambio de los usos del suelo y su impacto sobre los patrones de escurrimiento en la cuenca Lechuguilla-Ohuira-Navachiste, Sinaloa. A partir de la clasificación supervisada de imágenes de satélite Landsat $(1973,1986$ y 2000), se generaron mapas temáticos de cobertura y usos del suelo de la cuenca con niveles de exactitud $>85$ $\%$. En todos los años analizados la agricultura fue el uso del suelo dominante, cubriendo entre el $34 \%$ y $45 \%$ del área de la cuenca. Los porcentajes de cambio a nivel de paisaje fueron del $33 \%$ de 1973 a 1986 y del $27 \%$ de 1986 al 2000, asociados principalmente a las clases vegetación arbustiva y agricultura, las cuales registraron tasas medias de cambio anual entre 1973 y 2000 , de $2.1 \%$ y 0.6 $\%$, respectivamente. El impacto del cambio sobre los patrones de escurrimiento de la cuenca se evaluó con el modelo del número de curva. El volumen de escurrimiento medio anual se estimó en $198 \times 10^{6} \mathrm{~m}^{3}$ para $1973,302 \times 10^{6} \mathrm{~m}^{3}$ para 1986 y $197 \times 10^{6} \mathrm{~m}^{3}$ para el 2000 , que correspondieron a coeficientes de escurrimiento del $16 \%$, $20 \%$ y $23 \%$, respectivamente. Los resultados indican que para la zona de estudio el cambio en los volúmenes de escurrimiento depende más de los cambios en las tasas de precipitación que de los cambios en la cobertura y usos del suelo, debido a que predominan los suelos de textura fina con poca capacidad de infiltración y un potencial de escurrimiento resistente a los cambios de uso del suelo.

Palabras clave: cuenca, percepción remota, sistemas de información geográfica (SIG), número de curva, usos del suelo, escurrimiento

\begin{abstract}
In order to analyze trends in land use change in the Lechuguilla-Ohuira-Navachiste watershed (Sinaloa), as well as their impact on runoff patterns, a geographic information system (GIS) was integrated with land use/cover thematic maps, soil cartography and rainfall time-series. Land use/cover thematic maps, with accuracies $>85 \%$, were produced by supervised classification of Landsat satellite imagery (1973, 1986, and 2000). Agriculture was the main land use during the study period, covering between $34 \%$ and $45 \%$ of the basin area. At the landscape level, changes amounted to $33 \%$ from 1973 to 1986, and $27 \%$ from 1986 to 2000 , mainly associated with shrub vegetation and agriculture classes, which changed at mean annual rates of $2.1 \%$ and $0.6 \%$, respectively, from 1973 to 2000. To evaluate the impact of landscape changes on the watershed runoff, the curve number model was used, obtaining mean annual runoff volume estimates of $198 \times 106 \mathrm{~m}^{3}$ in 1973, $302 \times 10^{6} \mathrm{~m}^{3}$ in 1986 and $197 \times 10^{6} \mathrm{~m}^{3}$ in 2000. Those volumes correspond to
\end{abstract}


runoff coefficients of $16 \%, 20 \%$, and $23 \%$, respectively. The results indicate that changes in runoff volumes in the study area depend more on the variation of precipitation rates than those observed in land uses and cover changes, because of the high proportion of fine-textured soils, with little infiltration rates and runoff potential resistant to changes in land use.

Keywords: watershed, remote sensing, geographic information systems (GIS), curve number, land uses, runoff

\section{Introducción}

Los cambios en la cobertura y usos del suelo en una región son resultado de la acción sinérgica de factores endógenos y exógenos relacionados con el desarrollo económico, el crecimiento poblacional y con los cambios tecnológicos y ambientales. Estos cambios, que pueden ocurrir en varias formas, incluyendo modificaciones en área e intensidad de uso, son los principales factores que contribuyen al cambio global, no sólo en el sentido de que están presentes en casi cualquier parte del mundo, sino que también contribuyen al cambio climático global a través de las emisiones de gases de invernadero (Ojima et al., 1994; Lambin et al. 2003; Lambin y Geist, 2007).

Tanto a nivel local como regional los mayores impactos sobre los sistemas hidrológicos son causados por cambios en los patrones de cobertura y uso del suelo (Bhaduri et al., 2000). Registros históricos de parámetros relacionados con la calidad del agua han permitido demostrar que en humedales dentro de cuencas que han perdido parte de su cobertura vegetal natural, la calidad del agua declina (Childers y Gosselink, 1990; Agardy et al., 2005). Asimismo, los cambios en los usos del suelo alteran significativamente las características hidrológicas de la superficie de los terrenos modificando los patrones y tasas del flujo del agua, con la consiguiente alteración de los sistemas costeros acuáticos que dependen de la dinámica que sigan tanto los aportes hídricos continentales como los materiales terrígenos asociados. Si este tipo de modificaciones en el balance hídrico sucede sobre áreas amplias o críticas de una cuenca o región puede tener impactos inmediatos y a largo plazo, incluyendo el aumento en los volúmenes de escurrimiento y la reducción de los suministros de agua a los mantos freáticos (Bhaduri et al., 2000, 2001; Harbor, 1994; Ma, 2004).

En este sentido, los sistemas de información geográfica (SIG), además de ser una herramienta útil para modelar los cambios de cobertura y usos del suelo, pueden auxiliar en el estudio del impacto que estos cambios tienen sobre los patrones hidrológicos de las cuencas. El uso de los SIG ha permitido el desarrollo de modelos hidrológicos espacialmente distribuidos que consideran la variación espacial en los parámetros y variables que tienen que ver con el balance de agua en una cuenca, así como pasar de las evaluaciones de eventos discretos específicos a generar estimaciones de los impactos sobre la calidad y cantidad de agua a largo plazo (Bhaduri et al., 2000; Mendoza et al., 2002; Treviño et al., 2002).
A través de la integración y análisis de diferentes capas de información con un SIG es posible definir los patrones espaciales y temporales de los parámetros hidrológicos y describir a las cuencas ambientalmente; además de simular el balance hidrológico en unidades espaciales, el flujo de agua y transporte de materiales, así como los efectos de distintos eventos de perturbación (Mendoza et al., 2002). Los SIG se han utilizado para modelar los cambios en los patrones hidrológicos a nivel de cuenca o paisaje (Harbor, 1994; Ferrér et al., 1995; Bernal-Brooks et al., 2002; Mendoza et al., 2002; Hernández-Guzmán et al., 2008), estimar tasas de erosión (Symeonakis et al., 2007) y en evaluaciones de contaminación del agua por fuentes no puntuales (Bhaduri et al., 2000; Ma, 2004).

Entre los métodos de estimación de parámetros hidrológicos que pueden ser implementados con el auxilio de SIG, se encuentra el modelo de número de curva desarrollado por el Natural Resources Conservation Service del USDA (Departamento de Agricultura de Estados Unidos, por sus siglas en inglés) en 1986. El número de curva es un parámetro usado para describir el potencial de escurrimiento en áreas determinadas en función del uso del suelo, sus propiedades hidrológicas (capacidad de filtración) y el antecedente de precipitación (Melesse y Shih, 2002; Melesse et al., 2003).

Partiendo de las consideraciones anteriores, el presente estudio tuvo como objetivo integrar un sistema de información geográfica (SIG) con datos de percepción remota (imágenes Landsat), cartografía digital y registros históricos de lluvia para implementar el modelo del número de curva y estimar los cambios en los patrones de escurrimiento de la cuenca Lechuguilla-Ohuira-Navachiste localizada en el norte de Sinaloa dentro de la región con el mayor desarrollo agrícola del país.

\section{2. Área de Estudio}

La Cuenca Bahía Lechuguilla-Ohuira-Navachiste se localiza al norte del estado de Sinaloa frente a las aguas del golfo de California, entre los paralelos $24^{\circ} 45^{\prime} \mathrm{N}$ y $26^{\circ}$ $12^{\prime}$ ' $\mathrm{N}$ y los meridianos $108^{\circ} 28^{\prime} \mathrm{W}$ y $109^{\circ} 21^{\prime} \mathrm{W}$ (Figura 1). La cuenca pertenece a la Región Hidrológica Sinaloa No. 10; limita al noroeste con la cuenca del río El Fuerte y al sureste con la cuenca del río Sinaloa, ambas de la misma región hidrológica.

La cuenca junto con las lagunas costeras asociadas tiene una extensión de alrededor de $4,500 \mathrm{~km}^{2}(6.8 \%$ de 
la superficie estatal), de los que $91 \%$ están dentro de la provincia fisiográfica de la Llanura Costera del Pacífico (subprovincia Llanura Costera y Deltas de Sonora y Sinaloa); el resto forma parte de la subprovincia Pie de la Sierra, perteneciente a la Sierra Madre Occidental (INEGI, 2000). La cuenca, con una altura máxima de $658 \mathrm{msnm}$, posee una forma triangular, cuyo relieve próximo a la costa permite la presencia de valles que han sido ampliamente ocupados para usos agrícolas. También se localizan elevaciones secundarias, como la serranía de Navachiste, que inicia en la bahía Ohuira y se prolonga hasta la bahía de Topolobampo (INEGI, 1995).

El clima en la región va de seco muy cálido y cálido (BS) en las zonas altas a muy seco, muy cálido y cálido (BW) en la región costera. La temperatura promedio anual es de $26{ }^{\circ} \mathrm{C}$, siendo los meses de julio y agosto los más calurosos, con temperaturas promedio de $31{ }^{\circ} \mathrm{C}$, y de diciembre a febrero los más fríos, con temperaturas entre 19 ${ }^{\circ} \mathrm{C}$ y $20^{\circ} \mathrm{C}$. La precipitación anual promedio es de $334 \mathrm{~mm}$, siendo los meses más lluviosos julio, agosto, septiembre y octubre con precipitaciones mensuales promedio de 34 , 88,85 y $37 \mathrm{~mm}$, respectivamente. Las principales asociaciones vegetales son el bosque espinoso, bosque tropical caducifolio, vegetación halófila e hidrófila y matorral xerófito (INEGI, 1995).

En la parte terminal de la cuenca se encuentran asociadas ocho bahías (Figura 1), seis de ellas conforman dos sistemas acuáticos de grandes dimensiones: OhuiraTopolobampo y San Ignacio-Navachiste, los cuales contribuyen al desarrollo de actividades económicas como la acuicultura, servicios portuarios y la pesca.

\section{Métodos}

Para evaluar el impacto que los cambios de cobertura y usos del suelo han tenido sobre el potencial y volumen de escurrimientos de la cuenca Lechuguilla-Ohuira-Navachiste se integró un SIG con mapas temáticos de cobertura y usos del suelo generados por la clasificación de imágenes de satélite Landsat, cartografía digital editada por el Instituto Nacional de Estadística y Geografía (INEGI) y registros históricos de precipitación proporcionados por el Servicio Meteorológico Nacional (SMN). El SIG permitió analizar las tendencias de cambio del uso del suelo e implementar el modelo del número de curva para estimar los volúmenes de escurrimiento en la cuenca en tres escenarios de usos del suelo.

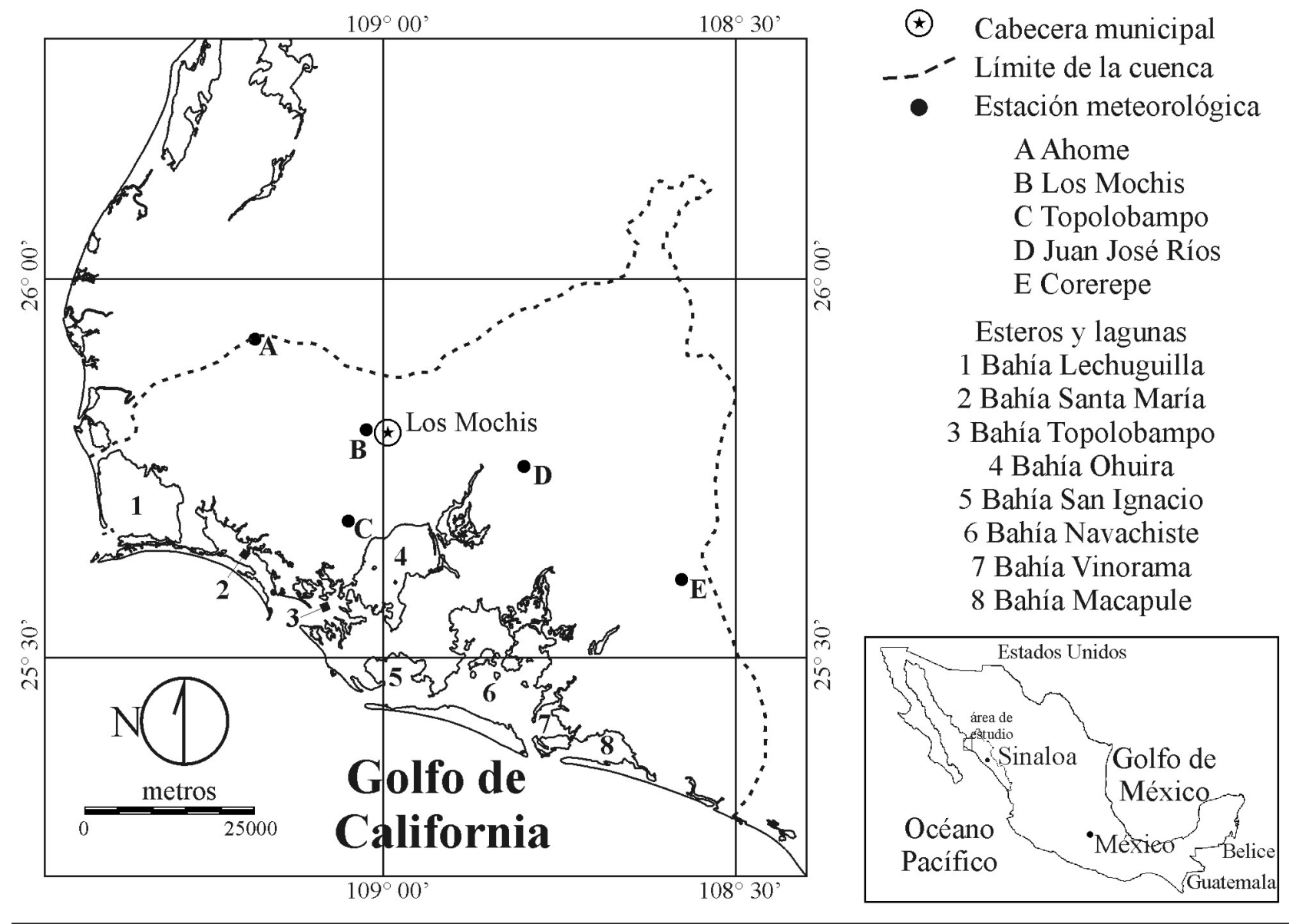

Figura 1. Área de estudio: cuenca Lechuguilla-Ohuira-Navachiste, Sinaloa, México. Se indica la posición de las estaciones meteorológicas que registraron los datos de precipitación utilizados en este estudio. 


\subsection{Cambios de uso del suelo}

Con el fin de detectar los cambios en la cobertura y uso del suelo se generaron mapas temáticos a partir del procesamiento digital de imágenes Landsat y datos auxiliares. En primera instancia, se integraron mosaicos del norte de Sinaloa mediante la concatenación de imágenes multi-espectrales Landsat MSS (NASA Landsat Program, 1973, 1986) de los path/row 33/42 y 34/42, del sistema mundial de referencia WRS2, con fechas de 1973 (24 de marzo) y 1986 (24 y 15 de marzo), respectivamente, ambas proporcionadas por el programa North American Landscape Characterization (NALC, http://edc2.usgs. gov/pathfinder/nalc_proj_camp.php). Un procedimiento similar se realizó con imágenes ETM+ (NASA Landsat Program, 2000), correspondientes al año 2000 (18 de mayo y 14 de abril). Esta integración de imágenes se realizó con el comando 'Mosaic' de Idrisi-Andes (Clark Labs, 2006), el cual permite igualar los valores digitales de brillantez entre las distintas imágenes involucradas en el proceso. Posteriormente, los mosaicos fueron acotados por un proceso de enmascaramiento a la poligonal de la cuenca Lechuguilla-Ohuira-Navachiste, cuyos vértices se digitalizaron de la cartas de hidrología superficial G12-9 Los Mochis y G12-6 Huatabampo escala 1: 250000 editadas por el INEGI (INEGI, 1986a, 1986b).

Los mosaicos multi-espectrales de cada año fueron clasificados de manera independiente en siete clases de cobertura y usos del suelo, siguiendo una técnica de clasificación supervisada con el algoritmo de máxima verosimilitud (Campbell, 2007). Posterior al proceso de clasificación, los polígonos de los poblados y las granjas camaronícolas fueron digitalizados sobre composiciones en falso color de las escenas de cada año. Los vectores resultantes (datos auxiliares) fueron transformados a formato raster para luego sobreponerlos, como dos nuevas clases, a los mapas temáticos producto de la clasificación, de tal forma que en éstos quedaron representadas nueve clases (Tabla 1). Estos mapas fueron filtrados con ventanas de 7 x 7 píxeles, usando la moda como medida de estandariza- ción, para reducir el efecto conocido como sal y pimienta, el cual consiste en la presencia de un número reducido de píxeles, de una o más clases, embebidos en una matriz de píxeles dominantes.

La exactitud del mapa de 2000 se evaluó a través de una matriz de error de treinta puntos de prueba por clase (Ramsey et al., 2001), seleccionados a partir de un muestreo aleatorio y validados en campo con un sistema de posicionamiento global (GPS por sus siglas en inglés) con exactitud de $\pm 4 \mathrm{~m}$. A partir de esta matriz se calculó la exactitud total y un estimador del coeficiente de kappa $\left(K^{\prime}\right)$ :

$K^{\prime}=\frac{N \sum_{i} n_{i i}-\sum_{i} n_{i+} n_{+j}}{N^{2} \sum_{i} n_{i+} n_{+j}}$,

donde $N$ es el número total de puntos de prueba, $n_{i i}$ es número de puntos de prueba correctamente clasificados (valor de la diagonal) de la clase $i, n_{i+}$ el número de puntos de prueba de la clase $i$ en los datos de clasificación (sumatoria del renglón) y $n_{+j}$ el número de puntos de prueba de la clase $i$ en los datos de referencia (sumatoria de la columna) (Congalton y Green, 1999).

Este coeficiente toma valores en el intervalo de -1.0 a 1.0, pero como existe una correlación mínima entre los datos de referencia y clasificados debida al azar, se esperan valores positivos de $K^{\prime}$, acotándose el intervalo de cero a uno. Si los valores de $K^{\prime}$ 'son significativamente diferentes de cero indican un proceso de clasificación mejor a una clasificación debida al azar. Asumiendo una distribución normal para el estimador del coeficiente de Kappa $\left(K^{\prime}\right)$, con el estadístico $\mathrm{Z}$ se puede probar $\mathrm{H}_{0}: K^{\prime}=0$ (Congalton y Green, 1999). Los mapas de 1973 y 1986 no fueron evaluados por carecer de datos de referencia históricos.

Una vez realizada la evaluación de la exactitud del mapa del 2000, éste fue corregido geométricamente con base en los parámetros espaciales de los mapas de 1973 y 1986 (2884 columnas, 2685 renglones, resolución de 60 m,

Tabla 1. Clases de cobertura y uso del suelo utilizadas en la generación de mapas temáticos de la cuenca Lechuguilla-Ohuira-Navachiste, Sinaloa, México, por clasificación supervisada de imágenes Landsat y digitalización de datos auxiliares.

\begin{tabular}{cll}
\hline ID & \multicolumn{1}{c}{ Clase } & \multicolumn{1}{c}{ Descripción } \\
\hline 1 & Lagunas y esteros & Sistemas estuarinos: bahías, esteros y lagunas \\
\hline 2 & Marismas & $\begin{array}{l}\text { Planicies de inundación intermedia por la acción intermareal que incluyen terrenos salinos con o sin cubierta vegetal, } \\
\text { principalmente Salichornia spp. y Batis sp. También se incluyen en esta clase algunas playas arenosas. }\end{array}$ \\
\hline 3 & Manglar & $\begin{array}{l}\text { Asociación vegetal de una o la combinación de las cuatro especies de mangle: mangle blanco (Laguncularia racemo- } \\
\text { sa), mangle rojo (Rhizophora mangle), mangle negro (Avicennia germinans) y mangle botoncillo (Conocarpus erec- } \\
\text { tus). En esta clase se consideran los parches de mangle en diferentes condiciones de dosel, inclusive mangle muerto. }\end{array}$ \\
\hline 4 & Selva & Bosque tropical caducifolio y bosque espinoso \\
\hline 5 & Vegetación arbustiva & Asociaciones de matorral xerófito, pastizales naturales y asociaciones vegetales en alguna etapa de sucesión. \\
\hline 6 & Agricultura & Terrenos dedicados a la práctica agrícola y otras actividades pecuarias incluyendo los pastizales inducidos \\
\hline 7 & Suelos desnudos & $\begin{array}{l}\text { Áreas erosionadas o terrenos agrícolas abandonados sin cubierta vegetal al momento en que se captaron las imágenes } \\
\text { de satélite }\end{array}$ \\
\hline 8 & Poblados & Asentamientos humanos urbanos y rurales. \\
\hline 9 & Camaronicultura & Estanquería para el cultivo de camarón \\
\hline & &
\end{tabular}


coordenadas UTM extremas 653 533, 2902345 y 762373 , 2797705 , zona 12 norte, datum NAD27) con el algoritmo del vecino más cercano y una función de mapeo cuadrática. A partir de los mapas se estimó el área de las diferentes clases en cada año y con estos datos se calculó la tasa de conversión, expresada como porcentaje:

$C=\left[\left(\frac{T_{2}}{T_{1}}\right)^{\frac{1}{n}}-1\right] 100$,

donde $C$ es la tasa de conversión, $T_{1}$ y $T_{2}$ corresponden a las áreas de la clase en los tiempos uno y dos, respectivamente, y $n$ es el número de años entre el tiempo uno y el tiempo dos (modificada de FAO, 1996).

\subsection{Modelo del número de curva}

Una vez obtenidos los mapas temáticos con una exactitud $K^{\prime} \geq 0.8$, se aplicó el modelo del número de curva desarrollado por el Servicio de Conservación del Suelo del Departamento de Agricultura de los Estados Unidos (SCS-USDA, por sus siglas en inglés), para evaluar el impacto que los cambios de cobertura y uso del suelo han tenido sobre el potencial y volumen de escurrimientos en la cuenca Lechuguilla-Ohuira-Navachiste.

El número de curva es un conjunto empírico de relaciones cuyos valores caen en el intervalo de 0 a 100, que representa las condiciones de la superficie terrestre en función del uso del suelo, la permeabilidad del suelo y los antecedentes de humedad (USDA, 1986; Harbor, 1994). Así mismo proporciona una forma para estimar la cantidad de agua de lluvia que escurriría en un periodo de 24 horas a partir de los datos de precipitación y condiciones del sitio.

Las propiedades hidrológicas y el uso del suelo se combinan para calcular el número de curva de un sitio, el cual es usado para predecir la profundidad de escurrimiento $(Q)$ para una profundidad de lluvia dada:

$Q=\frac{(P-I a)^{2}}{(P-I a)+S}$

donde $P$ es precipitación, $S$ el potencial máximo de retención e $I a$ es la abstracción inicial, todo evaluado en pulgadas. Los parámetros del modelo pueden calcularse por separado como:

$I a=0.2 S$

$Q=\frac{(P-0.2 S)}{P+0.8 S},(P \geq 0.2 S)$

$S=\left[\frac{1000}{C N}\right]-10$

donde $C N$ es el número de curva.

La abstracción inicial ( $I a$ ) incluye todas las pérdidas antes de que inicie el escurrimiento. Incluye el agua retenida en depresiones superficiales, agua interceptada por la vegetación, evaporación e infiltración. Se trata de un parámetro variable pero generalmente está correlacionada con los tipos de suelo y el uso del suelo. El modelo del número de curva original utiliza un valor para la razón de abstracción inicial $(\lambda=I a / S)$ de 0.2 (USDA, 1986), pero este valor ha sido considerado demasiado alto por varios autores y se ha propuesto sustituirlo por un valor de 0.05 (Hawkins et al., 2002; Jacobs y Srinivasan, 2005; Shi et al., 2009). A pesar de lo anterior y dado que en este estudio se utilizó la extensión L-THIA (Long-Term Hydrologic Impact Assessment) desarrollada por Engel et al. (2005) para el programa ArcView 3.2, se aplicó el valor de $I(a)$ $=0.2 S$ (utilizado en el estudio original) para estimar la profundidad de escurrimiento.

El modelo del número de curva trabaja con cuatro grupos hidrológicos de suelo (Tabla 2) y de cuatro a ocho coberturas/usos del suelo. A partir de la digitalización de las cartas edafológicas escala 1:250000 G12-9 Los Mochis y G12-6 Huatabampo (INEGI, 1984a, 1984b), se generó un mapa temático de tipos de suelo de la cuenca de acuerdo con la clasificación de FAO y se reclasificaron al grupo hidrológico de suelo correspondiente (Tabla 2). El mapa resultante, junto con los mapas temáticos de cobertura y usos del suelo generados anteriormente, se exportaron al programa ArcView 3.2 (ESRI, 1999) para producir de manera automática los mapas del número de curva de cada año con base en la combinación cobertura-uso del suelo/ grupo hidrológico del suelo.

Tabla 2. Grupos hidrológicos del suelo utilizados en el modelo del número de curva desarrollado por el Soil Conservation Service de Estados Unidos.

A. Arenas, tierras arenosas o tierras cubiertas de arena. Suelos con bajo potencial de escurrimiento y altas tasas de infiltración aun cuando están completamente mojados. Consisten principalmente de arenas o gravas profundas bien drenadas y tienen una alta transmisión de agua.

B. Marga de cienos o margas. Suelos con tasa de infiltración moderada cuando están completamente húmedos y consistentes de suelos moderadamente profundos a profundos, de moderadamente bien a bien drenados con texturas moderadamente finas a moderadamente gruesas.

C. Margas de arenas arcillosas. Suelos con tasa de infiltración baja cuando están fuertemente húmedos y consisten principalmente de suelos con una capa que impide el movimiento del agua hacia abajo y suelos con estructura de fina a moderadamente finas.

D. Margas arcillosas, margas arcillosas encenagadas, arenas arcillosas o arenas arcillosas encenagadas. Suelos con tasas muy bajas de infiltración cuando están completamente húmedos y consisten principalmente de suelos arcillosos con alto potencial de inflamiento, suelos con una capa de agua superior, suelos con una cubierta arcillosa cerca o en la superficie y suelos someros sobre material impermeable. 
Los mapas del número de curva se generaron al traslapar el mapa de los grupos hidrológicos de suelo con cada uno de los mapas de cobertura y usos del suelo generados por la clasificación de las imágenes Landsat. A cada combinación cobertura-uso del suelo/grupo hidrológico del suelo se le asignó, mediante reclasificación, el número de curva correspondiente para dos condiciones de antecedentes de humedad (AMC por sus siglas en inglés): la condición normal intermedia (AMC II), cuando la precipitación total en cinco días previos a la tormenta va de $36 \mathrm{~mm}$ a 53 $\mathrm{mm}$ en la época de crecimiento; y la condición modificada seca (AMC I), cuando los antecedentes de precipitación en cinco días son menores a los $36 \mathrm{~mm}$ en la época de crecimiento (Silveira et al., 2000; Patil et al., 2008).

Para este análisis, la clase lagunas fue excluida, considerando que se trata del depósito final del agua de escurrimiento de la cuenca. Por el contrario, las otras dos clases de humedales, marismas y manglar, fueron reclasificados en una única clase de humedales con un número de curva de 100 (Humedales-100), sin importar el grupo hidrológico de suelo, es decir superficies con potencial máximo de retención (S) igual a cero. Asimismo, la clase poblados se subdividió en dos clases: residencial de alta densidad (Residencial $A D$ ), el polígono de la ciudad de Los Mochis, y residencial de baja densidad (Residencial BD), los polígonos de los demás poblados. Por otra parte, las granjas camaronícolas fueron reclasificadas a humedales con número de curva de cero (Humedales-0) sin escurrimientos. $\mathrm{El}$ resto de las clases conservaron su nominación anterior.

Con registros históricos (1962-2002) de la precipitación diaria registrada en las estaciones meteorológicas Ahome, Los Mochis, Topolobampo, Juan José Ríos y Corerepe (Tabla 3, Figura 1) se estimó la precipitación total anual promedio en pulgadas de los años 1973, 1986 y 2000, considerando 10 años de antecedentes de lluvia. Cada uno de estos promedios se utilizó como la profundidad de precipitación $(P)$ que, junto con los mapas del número de curva, permitieron estimar la profundidad $(Q)$ y el volumen de escurrimiento medio anual de la cuenca $\left(V_{Q}\right)$ para cada año analizado. Adicionalmente, se estimó el volumen de precipitación $\left(V_{P}\right)$ y el coeficiente de escurrimiento $\left(C_{Q}\right)$ :

$V_{Q}=\sum_{i} Q_{i} A_{i}$ para toda $i$ combinación cobertura/uso del suelo-grupo hidrológico del suelo

$V_{P}=P A_{t}$,

$C_{Q}=\left[\frac{V_{Q}}{V_{P}}\right] 100$,

donde: $V_{Q}$ es el volumen de escurrimiento, $Q_{i}$ es la profundidad de escurrimiento para la combinación cobertura-uso del suelo/grupo hidrológico del suelo $i, \mathrm{~A}_{\mathrm{i}}$ es el área de la combinación cobertura-uso del suelo/grupo hidrológico del suelo $i, V_{P}$ es el volumen de precipitación, $P$ es la profundidad de precipitación, $A_{t}$ es el área total de la cuenca y $C_{Q}$ es el coeficiente de escurrimiento. Adicionalmente al volumen de escurrimiento medio anual de la cuenca $\left(V_{Q}\right)$, se estimó, con fines de comparación, la profundidad y el volumen de escurrimiento para un sólo evento de lluvia, considerando una precipitación de $71 \mathrm{~mm}$ (2.8 pulgadas), que fue el promedio del día más lluvioso registrado en cada uno de los años analizados.

\section{Resultados}

\subsection{Cambios de uso del suelo}

Los mapas generados por la clasificación supervisada de las imágenes Landsat de 1973, 1986 y 2000 se muestran en la Figura 2. El mapa temático de 2000 se produjo con una exactitud total del $89 \%$ y un estimador del coeficiente de kappa $\left(K^{\prime}\right)$ de 0.88 para un total de 240 puntos de prueba, resultando significativamente diferente de cero $(Z=$ $13.4, p<0.05)$ y asociado a una clasificación casi perfecta, de acuerdo con la escala propuesta por Landis y Koch (1977). Durante los recorridos de campo no se recabaron suficientes puntos de prueba para diferenciar adecuadamente la clase suelos desnudos de la clase agricultura, por lo que para este análisis se agruparon ambas clases. Dada la reducida proporción asociada con suelos desnudos en el 2000 , se considera que los errores de clasificación de esta clase no modifican significativamente los indicadores de exactitud total y los referentes a la clase agricultura, la

Tabla 3. Coordenadas geográficas y estadísticas básicas de la precipitación registrada de 1962 a 2002 en las estaciones meteorológicas ubicadas dentro de la cuenca Lechuguilla-Ohuira-Navachiste.

\begin{tabular}{|c|c|c|c|c|c|c|c|c|}
\hline \multirow{2}{*}{ Clave } & \multirow{2}{*}{ Estación } & \multicolumn{2}{|c|}{ Coordenadas } & \multirow{2}{*}{$\mathrm{N}$} & \multicolumn{4}{|c|}{ Precipitación anual (mm) } \\
\hline & & Latitud & Longitud & & Min & $\operatorname{Max}$ & Med & $\mathrm{s}$ \\
\hline A & Ahome & $25^{\circ} 55^{\prime}$ & $109^{\circ} 11^{\prime}$ & 40 & 10 & 588 & 252.9 & 171.3 \\
\hline B & Los Mochis & $25^{\circ} 48^{\prime}$ & $109^{\circ} 00^{\prime}$ & 31 & 68 & 684 & 357.6 & 144.0 \\
\hline $\mathrm{C}$ & Topolobampo & $25^{\circ} 37^{\prime}$ & $109^{\circ} 03^{\prime}$ & 32 & 28 & 953 & 308.4 & 173.4 \\
\hline $\mathrm{D}$ & Juan José Ríos & $25^{\circ} 45^{\prime}$ & $108^{\circ} 48^{\prime}$ & 14 & 155 & 683 & 383.5 & 160.9 \\
\hline $\mathrm{E}$ & Corerepe & $25^{\circ} 36^{\prime}$ & $108^{\circ} 35^{\prime}$ & 17 & 213 & 608 & 368.6 & 128.4 \\
\hline
\end{tabular}

$\mathrm{N}$ : número de años, Min: valor mínimo registrado, Max: valor máximo registrado, Med: promedio, s: desviación estándar. 

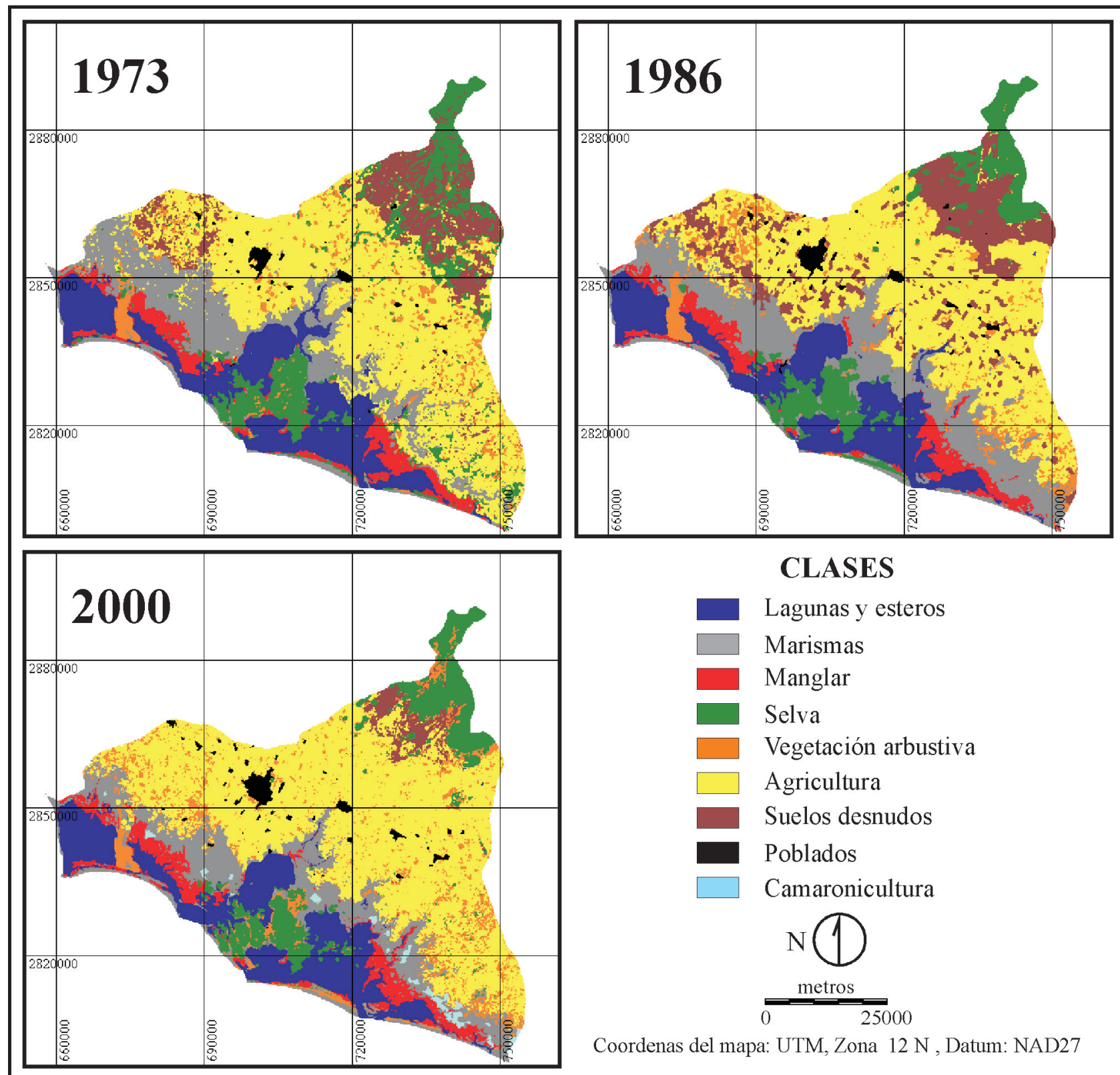

\section{CLASES}

Lagunas y esteros

Marismas

Manglar

Selva

Vegetación arbustiva

Agricultura

Suelos desnudos

Poblados

Camaronicultura
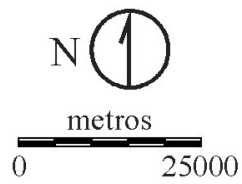

Coordenas del mapa: UTM, Zona $12 \mathrm{~N}$, Datum: NAD27

Figura 2. Mapas temáticos de cobertura y uso del suelo en la cuenca Lechuguilla-Ohuira-Navachiste, Sinaloa, México producidos por clasificación supervisada de imágenes Landsat y digitalización de datos auxiliares. (Coordenadas de los mapas UTM, zona 12 norte, Datum: NAD27).

cual registró 27 puntos correctamente clasificados de 30 puntos de referencia (exactitud del productor $=27 / 30=$ $0.9)$ y 35 puntos de clasificación (exactitud del usuario $=$ $27 / 35=0.77)$.

La exactitud total alcanzada es, en buena medida, resultado de la incorporación de datos auxiliares al proceso de clasificación, en este caso los polígonos de los poblados y las granjas camaronícolas, lo cual permitió clasificar estas categorías con $100 \%$ de exactitud. Asimismo, la clase lagunas, al tratarse de la única cobertura acuática, también se clasificó perfectamente y tuvo el mismo efecto en la exactitud total.

En el caso de la clasificación de las imágenes Landsat MSS de 1973 y 1986, se esperarían niveles de exactitud próximos a los obtenidos para la clasificación de 2000, aún cuando son de menor resolución espectral y espacial que las imágenes ETM+, dado que los criterios de selección de campos de entrenamiento, algoritmos de clasificación e incorporación de datos auxiliares (polígonos de poblados) fueron iguales (Ruiz-Luna y Berlanga-Robles, 1999; Munyati, 2000). Bajo este supuesto, y considerando una propagación multiplicativa del error al comparar mapas de diferentes fechas (Singh, 1989; Mas, 1999), las tasas de conversión estimadas en este estudio tendrían una exactitud de alrededor del $80 \%$, considerado aceptable para estudios de esta naturaleza.

En todos los años analizados la agricultura fue la clase dominante, cubriendo entre el $34 \%$ y el $45 \%$ del área de 
la cuenca. Por el contrario, las clases poblados y camaronicultura (esta última únicamente representada en el mapa de 2000) fueron las de menor porcentaje, alrededor del 1 $\%$ cada una (Tabla 4). A nivel de paisaje los porcentajes de cambio fueron $32 \%$ de 1973-1986, $27 \%$ de 1986-2000 y $33 \%$ de 1973-2000.

Las clases lagunas y manglar mantuvieron su área prácticamente constante, contrastando con las marismas, humedal que en los 27 años analizados perdió alrededor de 7500 ha con una tasa promedio anual de $-0.4 \%$ (Tabla 4).

La clase selva registró las mayores pérdidas de área en el periodo 1973-1986, siendo desplazada principalmente por las clases suelos agrícolas y agricultura, pero de 1986 a 2000 prácticamente mantuvo estable su extensión. Por su parte, la clase agricultura, si bien registró una tasa de cambio negativa en 1973-1986, para el segundo periodo analizado registró un incremento de la frontera agrícola de casi 47000 ha, con lo que se obtuvo un crecimiento neto de alrededor de 30000 ha con una tasa de crecimiento anual de $0.6 \%$ para todo el periodo analizado (Tabla 4 ).

La clase poblados, si bien en todos los años analizados representó un porcentaje mínimo dentro de la cuenca, mostró incrementos significativos en ambos periodos, presentándose un crecimiento más acelerado de 1973 a 1986.

4.2. Cambios en los patrones de escurrimiento (modelo del número de curva)

Se identificaron siete tipos de suelo de acuerdo con la clasificación de la FAO-UNESCO (Figura 3). Los Vertisoles cubren casi la mitad de la cuenca, seguidos por Solonchaks, que cubren alrededor del $27 \%$ (Tabla 5).

En los tres años analizados la combinación dominante de cobertura-uso del suelo/grupo hidrológico de suelo fue Agricultura/D, con un número de curva asociado de 85 en AMC II y 70 en AMC I, que cubrió entre el $36 \%$ y 44 $\%$ de la cuenca. La anterior combinación fue seguida por Humedales-100/C que en promedio cubrió el $20 \%$ de la cuenca. Exceptuando el valor de cero asociado a la clase Humedales-0, en la cuenca Lechuguilla-Ohuira-Navachis- te se encontraron valores de número de curva de 30 a 100 en AMC II y de 15 a 100 en AMC I (Figura 4).

La precipitación media anual, registrada en las seis estaciones meteorológicas ubicadas dentro de la cuenca, fue de $332 \mathrm{~mm}$ para el periodo de 1964 a 1973, $405 \mathrm{~mm}$ para el periodo de 1975 a 1986 y, finalmente, $229 \mathrm{~mm}$ para el periodo de 1991 a 2000 . La media ponderada de la profundidad de escurrimiento $(Q)$ con antecedentes de humedad normales (AMC II) en 1973 fue de $5.6 \mathrm{~cm}$, en 1986 de $8.4 \mathrm{~cm}$ y en el 2000 tomó un valor de $5.2 \mathrm{~cm}$. Con antecedentes de humedad modificados (AMC I) las medias ponderadas fueron de $1.8,3.3$ y 2.8 para 1973,1986 y 2000, respectivamente.

Consecuente con los resultados arriba señalados, los volúmenes de escurrimiento medio anual de la cuenca $\left(V_{Q}\right)$ estimado con AMC II fueron de $213 \times 10^{6} \mathrm{~m}^{3}$ en 1973,322 x $10^{6} \mathrm{~m}^{3}$ en 1986 y $199 \times 10^{6} \mathrm{~m}^{3}$ en el 2000 , en tanto que los coeficientes de escurrimiento fueron del $17 \%, 21 \% \mathrm{y}$ $23 \%$, respectivamente (Tabla 6). Con AMC I el $V_{Q}$ fue de $67 \times 10^{6} \mathrm{~m}^{3}$ en $1973,126 \times 10^{6} \mathrm{~m}^{3}$ en 1986 y $93 \times 10^{6} \mathrm{~m}^{3}$ en el 2000, con coeficientes de escurrimiento de $5 \%, 8 \%$ y 11 $\%$, respectivamente, con los valores más altos asociados a la región noroeste de la cuenca y a la zona dominada principalmente por usos de suelo agrícolas (Tabla 6, Figura 5).

De 1962 a 2002 se estimó una precipitación promedio de $71 \mathrm{~mm}$ (2.8 pulgadas) para un sólo evento de lluvia, con el cual se estimó el volumen de escurrimiento correspondiente, resultando en $99 \times 10^{6} \mathrm{~m}^{3}$ para $1973,110 \times 10^{6}$ $\mathrm{m}^{3}$ para 1986 y $91 \times 10^{6} \mathrm{~m}^{3}$ para 2000 , presentándose un promedio de $100 \times 10^{6} \mathrm{~m}^{3}$, una desviación estándar de 9.7 $\mathrm{x} 10^{6} \mathrm{~m}^{3}$ y un coeficiente de variación de $9.6 \%$.

\section{Discusión}

Debe señalarse que si bien la gran transformación agrícola del norte de Sinaloa se registró entre 1934 y 1940, impulsada por la reforma agraria y la construcción de presas y canales (Ortega, 1999), en la cuenca LechuguillaOhuira-Navachiste la actividad continuó mostrando una tendencia de crecimiento de 1973-2000, identificándose a

Tabla 4. Coberturas y usos del suelo la cuenca Lechuguilla-Ohuira-Navachiste, Sinaloa, México.

\begin{tabular}{|c|c|c|c|c|c|c|c|c|c|}
\hline \multirow[b]{3}{*}{ Cobertura/uso } & \multicolumn{6}{|c|}{ Áreas } & \multicolumn{3}{|c|}{ Tasa de conversión } \\
\hline & \multicolumn{2}{|c|}{1973} & \multicolumn{2}{|c|}{1986} & \multicolumn{2}{|c|}{2000} & \multirow{2}{*}{ 1973-1986 } & \multirow{2}{*}{$1986-2000$} & \multirow{2}{*}{$1973-2000$} \\
\hline & ha & $\%$ & ha & $\%$ & ha & $\%$ & & & \\
\hline Lagunas y esteros & 66344 & 14.6 & 64055 & 14.1 & 63826 & 14.1 & -0.3 & 0 & -0.1 \\
\hline Marismas & 66693 & 14.7 & 79118 & 17.4 & 59176 & 13.0 & 1.3 & -2.1 & -0.4 \\
\hline Manglar & 21918 & 4.8 & 22622 & 5.0 & 24602 & 5.4 & 0.2 & 0.6 & 0.4 \\
\hline Selva & 55317 & 12.2 & 41893 & 9.2 & 41601 & 9.2 & -2.1 & -0.1 & -1 \\
\hline Vegetación arbustiva & 23377 & 5.2 & 27031 & 6.0 & 40462 & 8.9 & 1.1 & 2.9 & 2.1 \\
\hline Agricultura & 173308 & 38.2 & 156756 & 34.6 & 203646 & 44.9 & -0.8 & 1.9 & 0.6 \\
\hline Suelos desnudos & 43084 & 9.5 & 56790 & 12.5 & 10124 & 2.2 & 2.1 & -11.6 & -5.2 \\
\hline Poblados & 3484 & 0.8 & 5259 & 1.2 & 6042 & 1.3 & 3.2 & 1 & 2.1 \\
\hline Camaronicultura & 0 & 0 & 0 & 0 & 4045 & 0.9 & nd & nd & nd \\
\hline TOTAL & 453524 & & 453524 & & 453524 & & & & \\
\hline
\end{tabular}




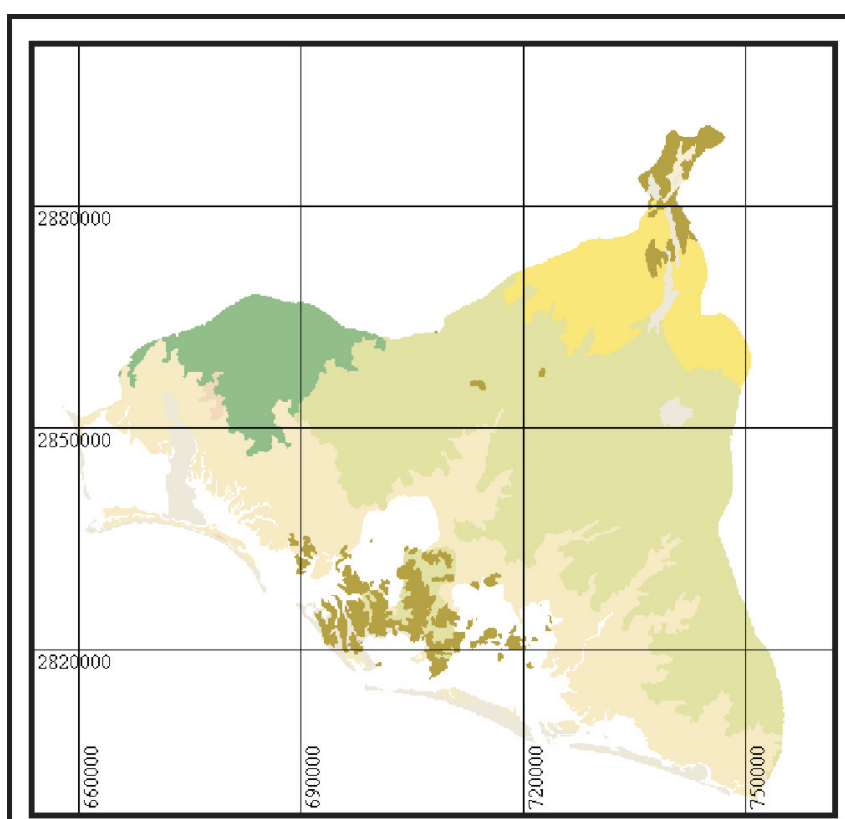

CLASIFICACIÓN FAO/UNESCO

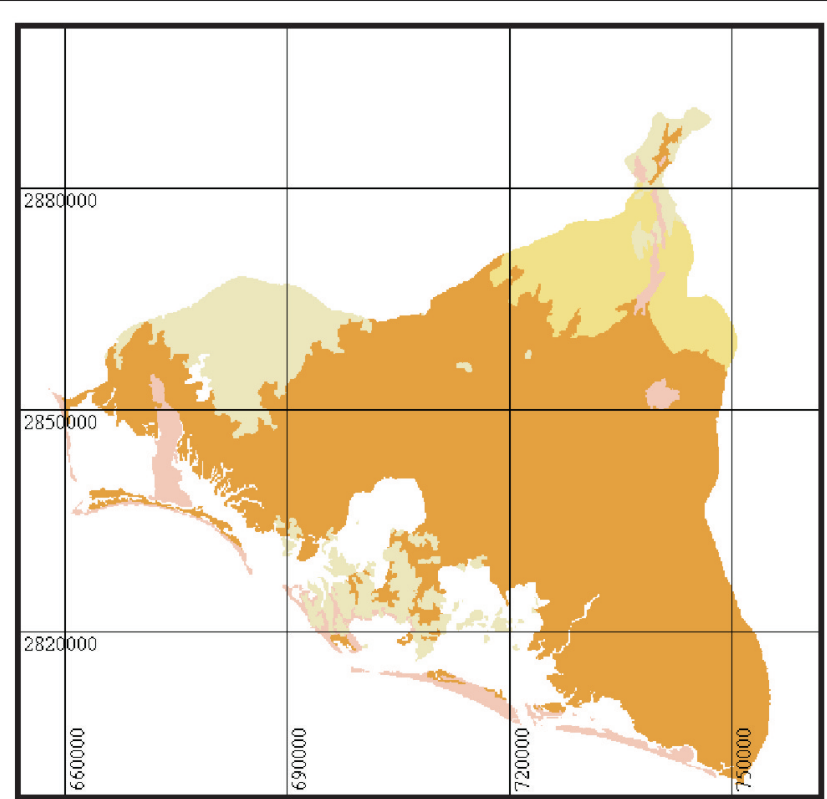

GRUPO HIDROLÓGICO DE SUELO

\begin{tabular}{|ll}
$\square$ & Regosol \\
$\square$ & Solonchack \\
$\square$ & Leptosol \\
$\square$ & Vertisol \\
$\square$ & Feozen \\
$\square$ & Xerosol \\
$\square$ & Castañozen
\end{tabular}
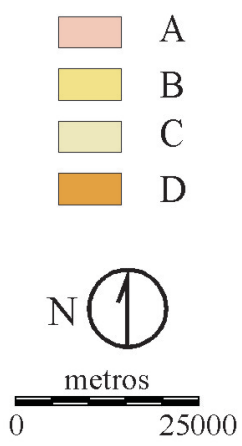

Coordenas del mapa: UTM, Zona $12 \mathrm{~N}$, Datum: NAD27

Figura 3. Suelos identificados en la cuenca Lechuguilla-Ohuira-Navachiste, Sinaloa, México de acuerdo a la clasificación de la FAO/UNESCO y reclasificados a los grupos hidrológicos de suelos.

Tabla 5. Extensión de suelos representados en la cuenca LechuguillaOhuira-Navachiste, Sinaloa, México, con su correspondencia a los grupos hidrológicos de suelo. No se incluye el área de esteros y lagunas costeras.

\begin{tabular}{lcrr}
\hline \multirow{2}{*}{ Unidad de Suelo (FAO) } & Grupo Hidrológico & \multicolumn{2}{c}{ Área } \\
\cline { 3 - 4 } & & \multicolumn{1}{c}{ (ha) } & \multicolumn{1}{c}{$\%$} \\
\hline Regosol & $\mathrm{A}$ & 17957 & 4.6 \\
Solonchack & $\mathrm{D}$ & 21653 & 5.6 \\
Leptosol & $\mathrm{C}$ & 176071 & 45.6 \\
Vertisol & $\mathrm{D}$ & 34934 & 9.0 \\
Feozem & $\mathrm{B}$ & 30508 & 7.9 \\
Xerosol & $\mathrm{C}$ & 932 & 0.2 \\
Castañozem & $\mathrm{D}$ & & \\
\hline
\end{tabular}

esta actividad como el principal agente transformador de los paisajes de la región durante el último cuarto del siglo pasado.

Los mosaicos de cobertura y usos del suelo se presen- tan como sistemas complejos con múltiples procesos de cambio, cada uno con su propia evolución y la mayoría de las veces asincrónicos. De acuerdo con Berlanga (2006), las tendencias de cambio en el uso del suelo dentro de la cuenca siguen un comportamiento estocástico, en el que el estado futuro del paisaje es independiente de los estados pasados y únicamente depende del estado actual.

En general, los cambios de cobertura y usos del suelo en la cuenca Lechuguilla-Ohuira-Navachiste no se han reflejado en la misma magnitud sobre los patrones de escurrimiento. Mientras que el porcentaje de cambio de cobertura y usos del suelo de 1973 a 1986 fue del $32 \%$ y de 1986 a 2000 de $27 \%$, los coeficientes de escurrimiento estimados con dos antecedentes de humedad únicamente variaron entre dos y cuatro puntos porcentuales. Asimismo, cuando se estimó el volumen de escurrimiento para un solo evento de precipitación (de $71 \mathrm{~mm}$ ) para los tres 


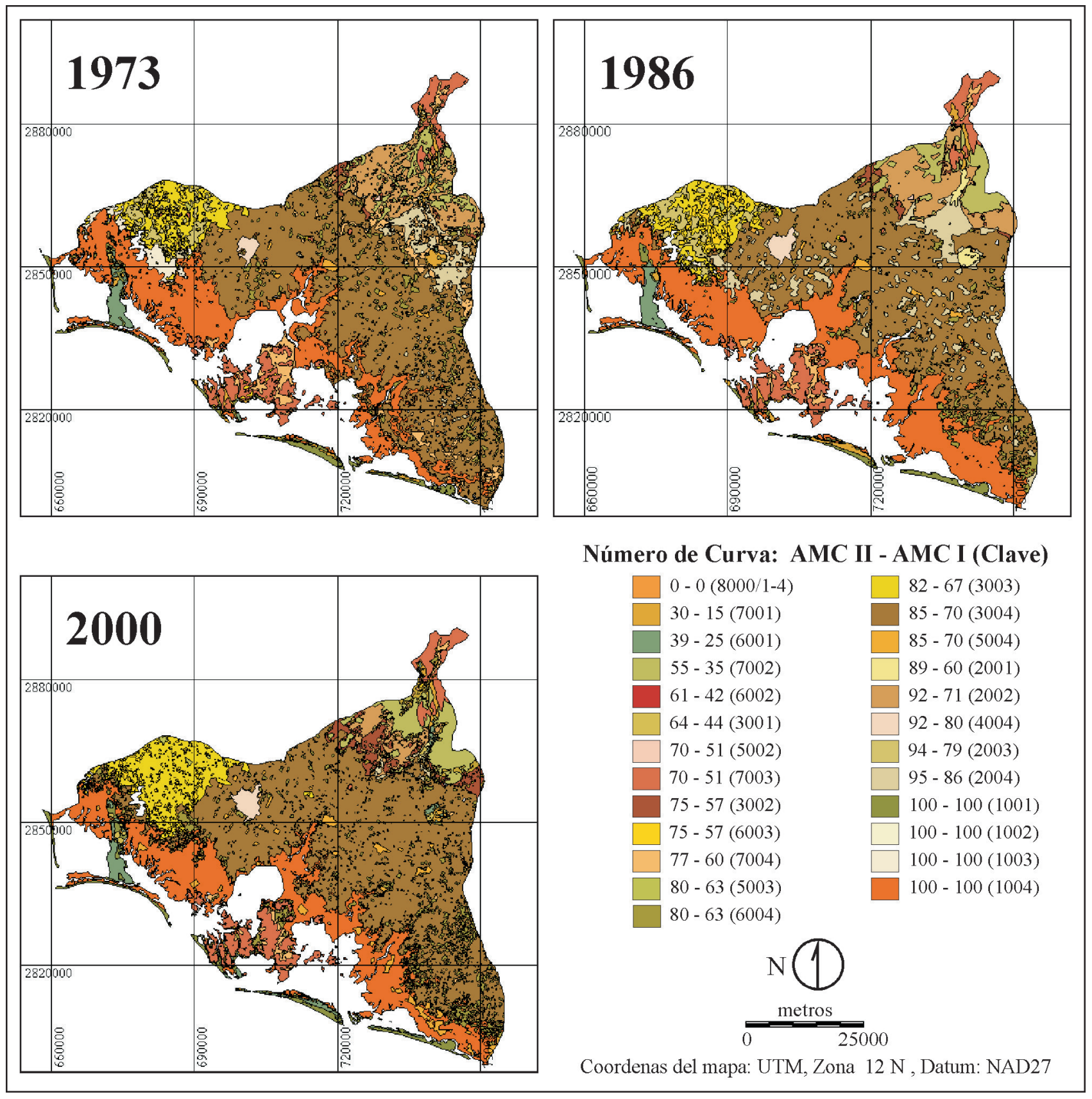

Figura 4. Números de curva identificados en la cuenca Lechuguilla-Ohuira-Navachiste, Sinaloa, México. La clave se refiere a las combinaciones cobertura del terreno/grupo hidrológico de suelo que se muestran en el Cuadro 6.

años analizados, el rango del volumen precipitado fue de 11 millones de metros cúbicos, con un coeficiente de variación $<10 \%$.

Este comportamiento en los volúmenes de escurrimiento dentro de la cuenca se atribuye a la naturaleza de los suelos predominantes. Dentro de los cuatro grupos hidrológicos de suelo, el tipo D (predominante en la zona de estudio), es el de mayor potencial de escurrimiento. Los Vertisoles, Solonchaks y Castañozems fueron agrupados en esta categoría, dado que se trata de suelos con alto contenido de arcillas, lo que les confiere una textura fina. Así, el grupo D cubrió el 72 \% de área de la cuenca y los cambios en el potencial de escurrimiento por cambios de uso del suelo son de menor magnitud en este tipo de suelos. Por ejemplo, mientras que en los suelos del grupo A el paso de una cobertura forestal a una agrícola o urbana significa un disminución del potencial máximo de retención $(S)$ de entre 18 y 20 unidades, en los suelos del grupo $\mathrm{D}$ la disminución por estos cambios es tan sólo de una a dos unidades. Esta situación sólo se ve parcialmente contrarrestada por la topografía de la región, que en su mayor parte se ubica dentro de la planicie costera, en la subprovincia fisiográfica Llanura Costera y Deltas de Sonora y Sinaloa, por lo que las pendientes son relativamente suaves 
Tabla 6. Cambios en los volúmenes de escurrimiento en la cuenca Lechuguilla-Ohuira-Navachiste, Sinaloa, México, estimados con el modelo del número de curva con antecedentes de humedad del suelo bajo condiciones normales (AMC II) y secas (AMC I).

\begin{tabular}{|c|c|c|c|c|c|c|c|c|}
\hline \multirow{3}{*}{$\begin{array}{l}\text { Cobertura/grupo } \\
\text { hidrológico }\end{array}$} & \multicolumn{4}{|c|}{ AMC II (normal) } & \multicolumn{4}{|c|}{ AMC I (modificado) } \\
\hline & \multirow{2}{*}{$\begin{array}{l}\text { Número } \\
\text { de curva }\end{array}$} & \multicolumn{3}{|c|}{ Volumen de escurrimiento medio anual $\left(\mathrm{m}^{3}\right)$} & \multirow{2}{*}{$\begin{array}{l}\text { Número } \\
\text { de curva }\end{array}$} & \multicolumn{3}{|c|}{ Volumen de escurrimiento medio anual $\left(\mathrm{m}^{3}\right)$} \\
\hline & & 1973 & 1986 & 2000 & & 1973 & 1986 & 2000 \\
\hline HUMEDAL-100/A & 100 & 0 & 0 & 0 & 100 & 0 & 0 & 0 \\
\hline HUMEDAL-100/B & 100 & 0 & 0 & 0 & 100 & 0 & 0 & 0 \\
\hline HUMEDAL-100/C & 100 & 0 & 0 & 0 & 100 & 0 & 0 & 0 \\
\hline HUMEDAL-100/D & 100 & 0 & 0 & 0 & 100 & 0 & 0 & 0 \\
\hline FORESTAL /A & 30 & 0 & 40406 & 49523 & 15 & 0 & 0 & 0 \\
\hline FORESTAL /B & 55 & 663260 & 2010114 & 2589700 & 35 & 26519 & 314078 & 591915 \\
\hline FORESTAL/C & 70 & 4565278 & 8602737 & 7078894 & 51 & 760862 & 2350756 & 2630674 \\
\hline FORESTAL/D & 77 & 8257230 & 3481354 & 2601523 & 60 & 2089768 & 1182347 & 1149213 \\
\hline ARBUSTIVA/A & 39 & 29819 & 163973 & 336075 & 25 & 0 & 10244 & 29227 \\
\hline ARBUSTIVA/B & 61 & 40243 & 51440 & 872641 & 42 & 4471 & 11789 & 272702 \\
\hline ARBUSTIVA/C & 74 & 1044291 & 3468333 & 2259738 & 57 & 249020 & 1145647 & 984685 \\
\hline ARBUSTIVA/D & 80 & 7893769 & 12929628 & 15389058 & 64 & 2317099 & 4782731 & 7177228 \\
\hline AGRÍCOLA/A & 64 & 63229 & 11114 & 317384 & 44 & 6430 & 2449 & 100077 \\
\hline AGRÍCOLA/B & 75 & 826855 & 1546305 & 4003459 & 57 & 183087 & 480340 & 1669885 \\
\hline AGRÍCOLA/C & 82 & 9459429 & 13593106 & 17069337 & 67 & 3044883 & 5384525 & 8339197 \\
\hline AGRÍCOLA/D & 85 & $\begin{array}{r}114048 \\
569\end{array}$ & 154309630 & 129484932 & 70 & 37624155 & 60735187 & 63038533 \\
\hline SUELOS DESNUDOS/A & 89 & 517444 & 3366615 & 464837 & 60 & 53573 & 533443 & 112500 \\
\hline SUELOS DESNUDOS/B & 92 & 27934278 & 35031604 & 9456169 & 71 & 5674997 & 9145192 & 3286340 \\
\hline SUELOS DESNUDOS/C & 94 & 10955257 & 17384950 & 0 & 79 & 3386174 & 6383701 & 0 \\
\hline SUELOS DESNUDOS/D & 95 & 23008251 & 58693298 & 1774948 & 86 & 10847756 & 30835450 & 1049878 \\
\hline RESIDENCIAL BD/B & 70 & 22911 & 41364 & 0 & 51 & 3818 & 11303 & 0 \\
\hline RESIDENCIAL BD/C & 80 & 118731 & 279151 & 360608 & 63 & 31898 & 96259 & 160606 \\
\hline RESIDENCIAL BD/D & 85 & 1163878 & 2464690 & 2035911 & 70 & 383958 & 970085 & 991164 \\
\hline RESIDENCIAL AD/D & 92 & 2021764 & 4567723 & 3170816 & 80 & 801526 & 2078611 & 1692050 \\
\hline HUMEDAL-0/C & 0 & 0 & 0 & 0 & 0 & 0 & 0 & 0 \\
\hline HUMEDAL-0/D & 0 & 0 & 0 & 0 & 0 & 0 & 0 & 0 \\
\hline \multicolumn{2}{|c|}{ Volumen total escurrido $\left(10^{6} \mathrm{~m}^{3}\right)$} & 213 & 322 & 199 & & 67 & 126 & 93 \\
\hline \multirow{2}{*}{\multicolumn{2}{|c|}{$\begin{array}{l}\text { Precipitación promedio en } 10 \text { años } \\
(\mathrm{mm}) \\
\text { Volumen precipitado en la cuenca } \\
\left(10^{6} \mathrm{~m}^{3}\right)\end{array}$}} & 332 & 405 & 229 & & 332 & 405 & 229 \\
\hline & & 1270 & 1530 & 865 & & 1270 & 1530 & 865 \\
\hline \multicolumn{2}{|c|}{ Coeficiente de escurrimiento (\%) } & 16.7 & 21.0 & 23.0 & & 5.3 & 8.3 & 10.8 \\
\hline
\end{tabular}

y de lomeríos bajos, lo que de alguna manera incrementa las tasas de infiltración, sin que se cuente con datos para estimar su magnitud.

Al respecto, cabe mencionar que los objetivos y alcances del proyecto de investigación que generaron los resultados aquí expuestos no permitieron tomar medidas directas del escurrimiento de la cuenca, por lo que no se generaron datos de campo para validar las estimaciones realizadas con el modelo del número de curva, pero, comparando los resultados obtenidos con los del INEGI (1995), que reportó un volumen de escurrimiento anual de 74 millones de metros cúbicos y un coeficiente de escurrimiento de $5.6 \%$, se observa que los valores estimados bajo antecedentes de humedad del suelo para condiciones normales (AMC II) se situaron entre dos y cuatro veces por arriba de estos valores. Recordando que el clima de la cuenca Lechuguilla-Ohuira Navachiste es de seco a muy seco, los valores del número de curva con antecedentes de humedad del suelo para condiciones secas (AMC I) parecen ser más adecuados para estimar el volumen de escurri- miento de la cuenca, pues los valores calculados con esta condición se aproximaron más a lo reportado por INEGI.

El modelo del número de curva no está diseñado para producir estimaciones exactas de los volúmenes de escurrimiento (Harbor, 1994). De hecho, la aplicación de este modelo bajo antecedentes de humedad del suelo con condiciones normales (AMC II) y un valor de la razón de abstracción inicial $(\lambda)$ de 0.2 tiende a sobrestimar los volúmenes de escurrimiento (Silveira et al., 2000; Patil et al., 2008; Shi et al., 2009). El valor de $\lambda$ de 0.2 es uno de los supuestos más ambiguos del modelo original del número de curva. Hawkins et al. (2002), a través de estudios de campo, midieron los escurrimientos de 307 cuencas de Estados Unidos y encontraron que con un valor de $\lambda$ igual a 0.05 se obtenía un mejor ajuste entre los volúmenes de escurrimiento observados y estimados con el modelo del número de curva; resultados similares fueron obtenidos por Jacobs y Srinivasan (2005), Lim et al. (2006) y Shi et al. (2009). En este estudio el programa de cómputo usado para calcular el número de curva, la profundidad y el volumen de escurrimiento utiliza un valor de $\lambda$ de 0.2 , 

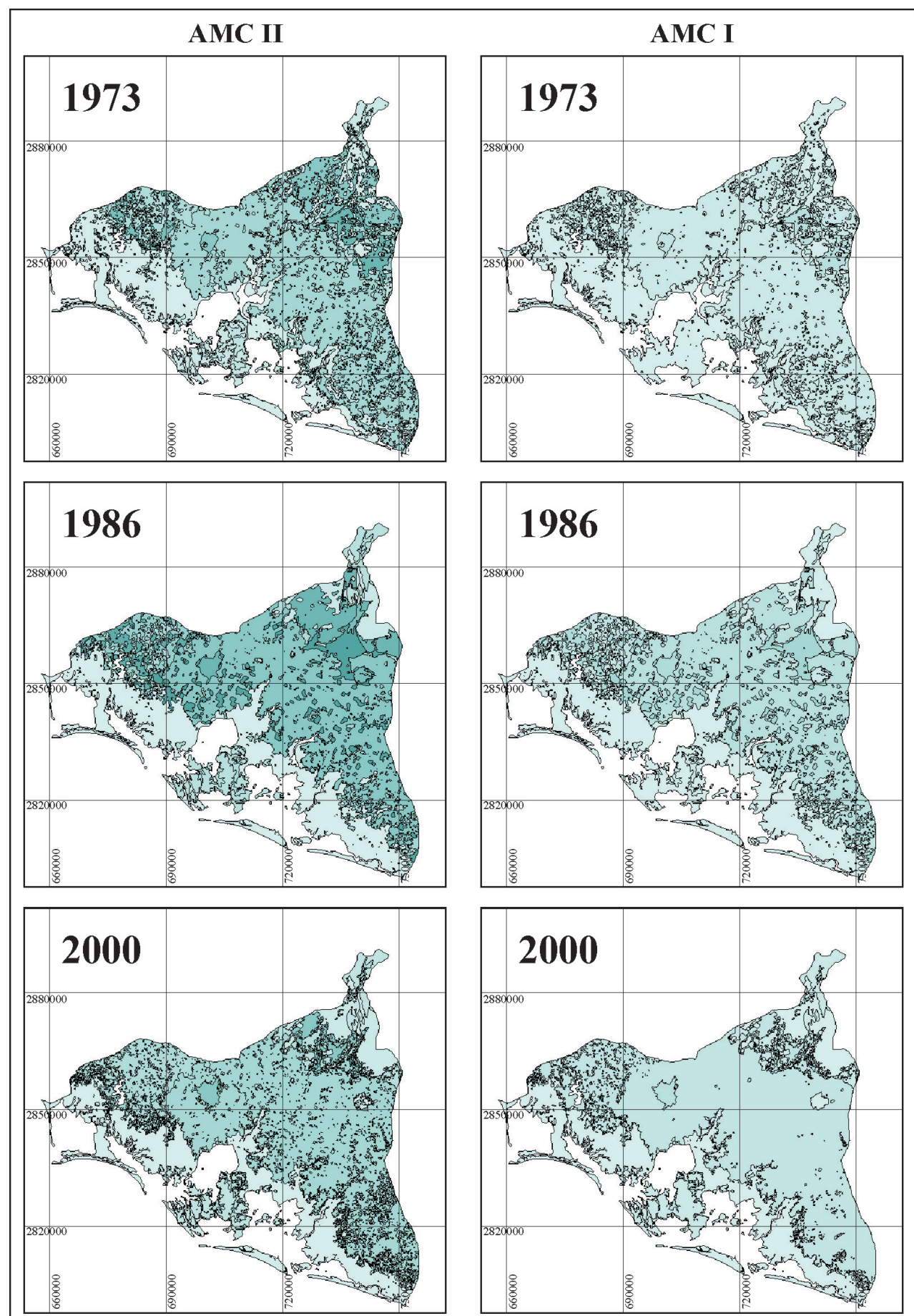

Volumen de escurrimiento medio anual $\left(\mathrm{m}^{3} /\right.$ celda)
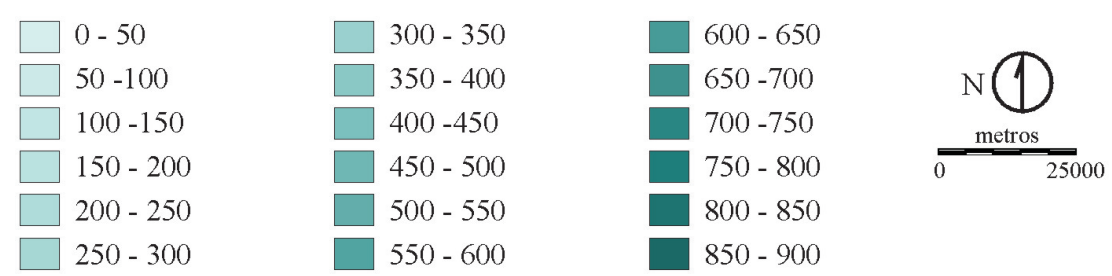

Coordenas del mapa: UTM, Zona $12 \mathrm{~N}$, Datum: NAD27

Figura 5. Volúmenes de escurrimiento en la cuenca Lechuguilla-Ohuira-Navachiste, Sinaloa, México estimados a partir del modelo del número de curva con antecedentes de humedad del suelo bajo condiciones normales (AMC II) y secas (AMC I). 
por lo que los volúmenes de escurrimiento podrían estar sobrevaluados, aún aquellos estimados para antecedentes de humedad del suelo para condiciones secas (AMC I).

Aún con sus limitaciones, el modelo del número de curva constituye un instrumento para generar indicadores de los impactos relativos del cambio de las coberturas y usos del suelo sobre los patrones de escurrimiento (Harbor, 1994). El modelo se aplicó para estimar el volumen de escurrimiento bajo diferentes escenarios de uso del suelo, tanto para un solo evento de lluvia así como para muchos años expresado como una estadística del promedio anual. En este último caso, un gran porcentaje del escurrimiento producido durante un año, más que resultado de eventos de lluvia prolongado, se deriva de la suma de escurrimientos generados durante eventos de precipitación menor que producen escurrimientos más frecuentes conforme los usos del terreno en la cuenca se incrementan. Así, el nivel de escurrimiento anual es importante en términos de la recarga de los mantos freáticos y el balance global de entrada de agua dulce a las zonas costeras (Leitch y Harbor, 1999).

\section{Conclusiones}

La evaluación de los impactos del cambio en el uso del suelo sobre los patrones hidrológicos de las cuencas es un aspecto fundamental para el establecimiento de las estrategias de manejo ambiental y prevención de desastres. En este sentido, la implementación del modelo del número de curva en una plataforma SIG constituye una herramienta de gran utilidad ya que, a partir de la integración de relativamente poca y accesible información (mapas de uso del suelo y tipos de suelo y datos de precipitación), permite estimar y monitorear de manera eficiente los cambios en los patrones de escurrimiento en regiones con diferentes características ambientales y niveles de perturbación.

Con la integración de un SIG se analizaron las tendencias de cambio de uso del suelo y se implementó el modelo del número de curva para la cuenca Lechuguilla-OhuiraNavachiste, encontrándose que se trata de un paisaje dominado por las coberturas agrícolas, condición que se presenta por lo menos desde la década de los setenta del siglo XX. Si bien existe un dominio particular de la agricultura sobre el paisaje de la cuenca, las coberturas naturales abarcan el $41 \%$ de la misma y en la planicie costera forman un cúmulo de ambientes interrelacionados cuya conectividad debe de ser considerada en las propuestas de ordenamiento y conservación de la región. En la cuenca predominan los suelos de textura fina con poca capacidad de infiltración, por lo que los cambios de cobertura y uso del suelo no se reflejaron en la misma magnitud en el potencial de escurrimiento de la cuenca. Los coeficientes de escurrimiento se mantuvieron relativamente constantes y las variaciones en el volumen de escurrimiento medio anual se deben más a las variaciones en la precipitación que a los cambios de uso del suelo.

\section{Agradecimientos}

Los autores agradecen al CONACYT y a la SEMARNAT por el financiamiento al proyecto del Fondo Sectorial de Investigación Ambiental SEMARNAT-2002-C010112/A-1. También se agradece al Servicio Meteorológico Nacional por facilitar los datos de precipitación utilizados en este estudio.

\section{Referencias}

Agardy, T., Alder, J., Dayton, P., Curran, S., Kitchingman, A., Wilson, M., Catenazzi, A., Restrepo, J., Birkeland, C., Blaber, S., Saifullah, S., Brach, G., Boersma, D., Nixon, S., Dungan, P., Davidson, N., Vörösmarty, C., 2005, Coastal system, in Hassan, R., Scholes, R., Ash, N.J. (eds.), Ecosystems and human well-being: Current state and trends: Londres, Island Press, 513-549.

Berlanga, C.A., 2006, Caracterización de los paisajes costeros de Sinaloa y norte de Nayarit, México a través del análisis de los patrones de cobertura del terreno: México, Universidad Nacional Autónoma de México, Instituto de Ciencias del Mar y Limnología, tesis doctoral, 204 p.

Bernal-Brooks, F., Gómez-Tagle, A., Alcocer, J., 2002, Lake Patzcuaro (Mexico): a controversy about the ecosystem water regime approached by field references, climatic variables, and GIS: Hydrobiologia, 467, 187-197.

Bhaduri, B., Harbor, J., Engel, B., Grove, M., 2000, Assessing watershedscale, long-term hydrologic impacts of land use change using a GIS-NPS model: Environmental Management 26, 643-658.

Bhaduri, B., Minner, M., Tatalovich, S., Harbor, J., 2001, Long-term hydrologic impact of land use change: a tale of two models: Journal of Water Resources Planning and Management, 127, 13-19.

Campbell, J.B., 2007, Introduction to remote sensing: Londres, Taylor and Francis, $626 \mathrm{p}$.

Childers, D.L., Gosselink, J.G., 1990, Assessment of cumulative impacts to water quality in a forested wetland landscape: Journal of Environmental Quality, 19, 455-464.

Clark Labs, 2006, Idrisi Andes Edition (15.01) (programa informático): Worcester, Massachusetts, Clark Labs, Clark University, 1 CD-ROM

Congalton, R.G., Green, K., 1999, Assessing the accuracy of remote sensing data: Principles and Practices: Boca Raton, Florida, EUA, Lewis Publisher, 137 p.

Engel, B.A., Harbor, J., Muthukrishnan, S., Pandey, S., Lim, K.J., Theller, L., 2005, L-THIA NPS. (Long-term hydrologic impact assessment and non point source pollutant model): EUA, Purdue University/ United States Environmental Protection Agency, manual, $46 \mathrm{p}$.

Environmental Systems Research Institute (ESRI), 1999, ArcView GIS 3.2 (programa informático): Redlands, California, Environmental Systems Research Institute Inc., 1 CD-ROM.

FAO, 1996, Forest resources assessment 1990. Survey of tropical forest cover and study of change processes: Roma, FAO Forestry Paper 130,152 p.

Ferrér, M., Rodríguez, J., Estrela, T., 1995, Generación automática del número de curva con sistemas de información geográfica: Ingeniería del Agua, 2, 43-58.

Harbor, J., 1994, A practical method for estimating the impact of land use change on surface runoff, groundwater recharge and wetland hydrology: Journal of the American Planning Association, 60, 95-108.

Hawkins, R.H., Jiang, R., Woodward, D.E., Hjelmfelt, A.T., Van Mullen, J.E., 2002, Runoff curve number method: examination of the initial abstraction ratio, in Proceedings of the Second Federal Interagency Hydrologic Modeling Conference, Las Vegas, Nevada: Lakewood, Colorado, EUA, United States Geological Survey, 1-12.

Hernández-Guzmán, R., Ruiz-Luna, A., Berlanga-Robles, C.A., 2008, Assessment of runoff response to landscape changes in the San 
Pedro subbasin (Nayarit, Mexico) using remote sensing data and GIS: Journal of Environmental Science and Health Part A, 43, 1471-1482.

Instituto Nacional de Estadística, Geografía e Informática (INEGI), 1984a, Carta edafológica, Huatabampo G12-6, 1:250000: México, D.F., Instituto Nacional de Estadística, Geografía e Informática, 1 mapa.

Instituto Nacional de Estadística, Geografía e Informática (INEGI), 1984b, Carta edafológica, Los Mochis G12-9, 1:250000: México, D.F., Instituto Nacional de Estadística, Geografía e Informática, 1 mapa.

Instituto Nacional de Estadística, Geografía e Informática (INEGI), 1986a, Carta hidrológica de aguas superficiales, Huatabampo G12-6, 1:250000: México, D.F., Instituto Nacional de Estadística, Geografía e Informática, 1 mapa.

Instituto Nacional de Estadística, Geografía e Informática (INEGI), 1986b, Carta hidrológica de aguas superficiales, Los Mochis G12-9, 1:250000: México, D.F., Instituto Nacional de Estadística, Geografía e Informática, 1 mapa.

Instituto Nacional de Estadística, Geografía e Informática (INEGI), 1995 , Estudio hidrológico del Estado de Sinaloa: Aguascalientes, México, Instituto Nacional de Estadística Geografía e Informática, 88 p.

Instituto Nacional de Estadística, Geografía e Informática (INEGI), 2000 , Guasave, Estado de Sinaloa. Cuaderno estadístico municipal: Aguascalientes, México, Instituto Nacional de Estadística Geografía e Informática, $225 \mathrm{p}$.

Jacobs, H., Srinivasan, R., 2005, Effects of curve number modification on runoff estimation using WSR-88D rainfall data in Texas watersheds: Journal of Soil and Water Conservation, 60, 274-279.

Lambin, E.F., Geist, H.J., 2007, Causes of land-use and land-cover change, in Cutler, J.C. (ed.), The Encyclopedia of Earth (en línea): Washington D.C., Environmental Information Coalition, National Council for Science and the Environment, publicado 7 de agosto de 2007, disponible en <http://www.eoearth.org/article/ Causes_of_land-use_and_land-cover_change $>$, consultado $10 \mathrm{de}$ octubre de 2009.

Lambin, E.F., Geist, H.J., Lepers, E., 2003, Dynamics of land use and land cover change in tropical regions: Annual Reviews of Environment and Resources, 28, 205-241.

Landis, J.R., Koch, G.G., 1977, The measurement of observer agreement for categorical data: Biometrics, 33, 159-174.

Leitch, C., Harbor, J., 1999, Impacts of land use change on freshwater runoff into the near-coastal zone, Holetown Watershed, Barbados: Comparisons of long-term to single-storm effects: Journal of Soil and Water Conservation, 54, 584-592.

Lim, K.J., Engel, B.A., Muthukrishnan, S., Harbor, J., 2006, Effects of initial abstraction and urbanization on estimated runoff using $\mathrm{CN}$ technology: Journal of the American Water Resources Association, 42, 629-643.

Ma, Y., 2004, L-THIA: A useful hydrologic impact assessment model: Nature and Science, 2, 68-73.

Mas, J.F., 1999, Monitoring land-cover changes: a comparison of change detection techniques: International Journal of Remote Sensing, 20, 139-152.

Melesse, A.M., Shih, S.F., 2002, Spatially distributed storm runoff depth estimation using Landsat images and GIS: Computers and Electronics in Agriculture, 37, 173-183.

Melesse, A.M., Graham, W.D., Jordan, J.D., 2003, Spatially distributed watershed mapping and modeling: GIS-based storm runoff response and hydrograph analysis: Part 2: Journal of Spatial Hydrology, $3,1-28$.

Mendoza, M., Bocco, G., Bravo, M., 2002, Spatial prediction in hydrology: status and implications in the estimation of hydrological processes for applied research: Progress in Physical Geography, 26, 319-338.

Munyati, C., 2000, Wetland change detection on the Kafue Flats, Zambia, by classification of a multitemporal remote sensing image dataset: International Journal of Remote Sensing, 21, 1787-1806.

NASA Landsat Program, 1973, Landsat Multispectral Scaner (MSS) imagery path/row 33/42, 34/42 (CD-ROM): Las Vegas, Nevada, North
American Landscape Characterization, 2 CD-ROM.

NASA Landsat Program, 1986, Landsat Multispectral Scaner (MSS) imagery path/row 33/42, 34/42 (CD-ROM): Las Vegas, Nevada, North American Landscape Characterization, 2 CD-ROM.

NASA Landsat Program, 2000, Landsat Enhanced Thematic Mapper Plus $(\mathrm{ETM}+)$ imagery path/row 33/42, 34/42 (CD-ROM): Washington, D.C., United States Geological Survey, 2 CD-ROM.

Ojima, D.S., Galvin, K.A., Turner II, B.L., 1994, The global impact of land-use change: BioScience, 44, 300-304.

Ortega, N.S., 1999, Breve historia de Sinaloa: México, Fideicomiso Historia de las Américas, El Colegio de México-Fondo de Cultura Económica, $332 \mathrm{p}$

Patil, J.P., Sarangi, A., Singh, A. Ahmad, T., 2008, Evaluation of modified $\mathrm{CN}$ methods for watershed runoff estimation using a GIS-based interface: Biosystems Engineering, 100, 137-146.

Ramsey III, E.W., Nelson, G.A., Sapkota, S.K., 2001, Coastal change analysis program implemented in Louisiana: Journal of Coastal Research, 17, 53-71.

Ruiz-Luna, A., Berlanga-Robles, C.A., 1999, Modifications in coverage patterns and land use around the Huizache-Caimanero lagoon system, Sinaloa, México: A multi-temporal analysis using Landsat images: Estuarine Coastal and Shelf Science, 49, 37-44.

Shi, Z.H., Chen, L.D., Fang, N.F., Qin, D.F., Cai, C.F., 2009, Research on the SCS-CN initial abstraction ratio using rainfall-runoff event analysis in the Three Gorges Area, China: Catena, 77, 1-7.

Silveira, L., Charbonnier, F., Genta, J.L. 2000, The antecedent soil moisture condition of the curve number procedure: Hydrological Sciences Journal, 45, 3-12.

Singh, A., 1989, Digital change detection techniques using remotely-sensed data: International Journal of Remote Sensing, 10, 989-1003

Symeonakis, E., Calvo-Cases, A, Arnau-Rosalen, E., 2007, Land use change and land degradation in Southeastern Mediterranean Spain: Environmental Management, 40, 80-94.

Treviño, G.E., Muñoz, R.C.A., Cavazos, C.C., Barajas, C.L., 2002, Evaluación del flujo hídrico superficial en la Sierra de San Carlos, Tamaulipas: Ciencia UANL, 5, 525-530.

United States Department of Agriculture (USDA), 1986, Urban hydrology for small watersheds: Washington, D.C., United States Department of Agriculture, Technical Release 55, $164 \mathrm{p}$.

Recibido: 06/11/2009

Recibido corregido: 26/01/2010

Aceptado: 26/10/2010 